\title{
Simulation Study on HPDC Process with Automobile Part by CAE
}

\author{
B.J. Lee \\ Dept. of Electronic Engineering \\ Namseoul University \\ Chonan, South Korea
}

\author{
H.K. Kwon \\ Industrial \& Management Engineering \\ Namseoul University \\ Chonan, South Korea
}

\begin{abstract}
In this research, in order to optimize casting design of an automobile part (Housing), Computer Aided Engineering (CAE) was performed by using the simulation software (AnyCasting). The simulation results were analyzed and compared with the several casting designs. During the filling process, internal porosities caused by air entrap were predicted and reduced remarkably by the modification of the gate system and the configuration of overflows. With the solidification analysis, internal porosities caused by the solidification shrinkage were predicted and reduced by the modification of the gate system. For making better permanent High Pressure Die Casting (HPDC) mold, some vacuum systems are proposed in order to reduce internal porosities caused by the filling process.
\end{abstract}

Keywords-CAE simulation; HPDC; MFA; gate design; FDM

\section{INTRODUCTION}

The method of HPDC is one of the most important techniques for manufacturing automobile parts and electronic parts, and one of the economical casting techniques that can manufacture complex shapes at one time. As the market demands for shorter design and manufacturing lead-time, good dimensional accuracy, overall product quality and rapid change of product design and process configuration are increasingly significant. Also, the casting companies are required to make the manufacturing term shorter, to reduce the manufacturing expenses and to get high quality in the international competitive society of globalization $[1,2]$.

When manufacturing HPDC mold, generally, the casting layout design should be considered based on the relation among injection system, casting condition, gate system, and cooling system. Computer-aided engineering (CAE) simulation technology helps practitioners to generate, verify, validate and optimize the design solutions. CAE simulation is also a most technologically efficient and cost effective technology for analysis, prediction and evaluation of casting product quality and defects $[1,2]$.

In this research, CAE simulation was performed by using the simulation software (Any casting) in order to optimize casting design of an automobile part (Housing) as shown on Figure 1. The simulation results were analyzed and compared with experimental results. During the filling process, internal porosities caused by air entrap were predicted and reduced remarkably by the modification of the gate system and the configuration of overflow. With the solidification analysis, internal porosities caused by the solidification shrinkage were predicted and reduced by the modification of the gate system.

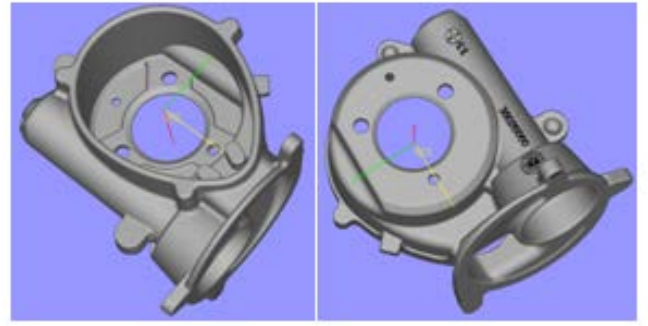

FIGURE I. CAD DATA FOR GEAR HOUSING.

\section{NUMERICAL SIMULATION}

In this research, the commercial package (Any Casting) was used to optimize a casting design before fabricating production HPDC mold. The software had been developed by Any Casting Co., LTD. and employed a hybrid method mixing a PM (Porous Media) Method and a Cut-Cell Method that complements a drawback of the conventional FDM (finite difference method) rectangular mesh.

\section{A. Modeling of the Casting Process}

The action (flow of the melted metal) in the HPDC process is the high pressure generated by the fast movement of plunge in the chamber. Any Casting employed a hybrid method to analyze the flow of the melted metal and had been designed for analyze three-dimensional fluid flow with the free surface and boundary. The flow of the melted metal is considered any non-Newtonian and non-linear rheological properties. Making the modeling of the filling process, there are three phenomena (such as melt momentum balance, mass balance and energy balance) to be represented and modeled. The phenomena can be described by the following governing equations:

Continuity equation:

$$
\frac{\partial \rho}{\partial t}+\frac{\partial}{\partial x_{j}}\left(\rho U_{j}\right)=0
$$

Momentum equation (Navier-stokes):

$$
\frac{\partial}{\partial t}\left(\rho U_{i}\right)+\frac{\partial}{\partial x_{j}}\left(\rho U_{j} U_{i}\right)=\frac{\partial \rho}{\partial x_{i}}+\frac{\partial}{\partial x_{j}}\left(\mu \frac{\partial U_{i}}{\partial x_{j}}\right)+\rho g_{i}
$$

Energy equation: 


$$
\frac{\partial}{\partial t}\left(\rho C_{p} T\right)+\frac{\partial}{\partial x_{j}}\left(\rho C_{p} U_{j} T\right)=\frac{\partial}{\partial x_{j}}\left(\lambda \frac{\partial T}{\partial x_{j}}\right)+Q
$$

Volume of Fluid (VOF):

$$
\frac{\partial F}{\partial t}+U_{j} \frac{\partial F}{\partial x_{j}}=0,0 \leq F \leq 1
$$

Where $\mathrm{t}$ is time, $\mathrm{x}$ is space, $\mathrm{p}$ is density, $\mathrm{u}$ is viscosity, $\mathrm{g}$ is gravity, $\mathrm{Cp}$ is heat capacity, $\lambda$ is conductivity, $\mathrm{F}$ is volume, $\mathrm{U}$ is velocity, T is temperature, Ts is solid temperature, and Q is heat source.

1) Geometry model: The CAD models are created in Unigraphics (a commercial CAD/CAM package for product design and development), and converted into STL format with Magics RP (a commercial CAD package for product design). AnyCasting imports directly the generated STL models for the filling and solidification simulation. As shown on Figure 2, there are 3 different casting designs used for finding out the best result. The case 1 has two symmetrical principal gates comparing with Case 2 and 3 . The case 2 and 3 have a principal gate and an additional branch gate. Branch gate is used for filling uniformly the remote area which is far from the principal gate. As shown on Figure 3, the main difference of case 2 and 3 is the filling direction on the gates into the cavity.

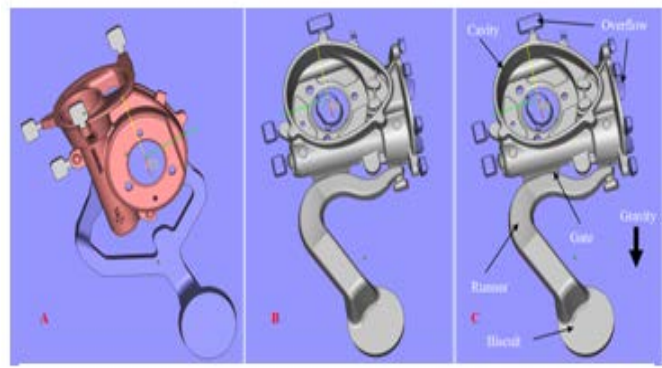

FIGURE II. CASTING MODEL OF HOUSING: (A) CASE 1; (B) CASE 2; (C) CASE 3.

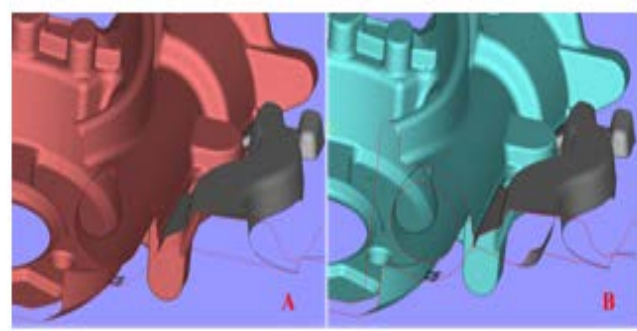

FIGURE III. SECTION VIEW OF THE GATE: (A) CASE 2; (B) CASE 3.

2) Pre-processing and mesh generation:ADC12 (AlSi9Cu3) was used for the cast material and SKD 61 was for the die material. Initial temperature and casting temperature for the cast material were 6800C and 6000C, respectively. Initial temperature and casting temperature for the mold were 2000C and 2800C, respectively.
TABLE I Condition for the CAE simulation.

\begin{tabular}{|c|l|l|}
\hline \multirow{4}{*}{ Part } & Material & ADC12 \\
\cline { 2 - 3 } & Liquidus Line & $580^{\circ} \mathrm{C}$ \\
\cline { 2 - 3 } & Solidus Line & $515^{\circ} \mathrm{C}$ \\
\cline { 2 - 3 } & Initial Temperature & $640^{\circ} \mathrm{C}$ \\
\cline { 2 - 3 } & Weight for casting & $820 \mathrm{~g}$ \\
\hline \multirow{2}{*}{ Mold } & Material & SKD 61 \\
\cline { 2 - 3 } & Initial Temperature & $200{ }^{\circ} \mathrm{C}$ \\
\hline \multirow{3}{*}{ Plunger } & Diameter & $70 \mathrm{~mm}$ \\
\cline { 2 - 3 } & Slow Velocity & $0.40 \mathrm{~m} / \mathrm{s}$ \\
\cline { 2 - 3 } & High Velocity & $1.60 \mathrm{~m} / \mathrm{s}$ \\
\hline
\end{tabular}

The velocity of melt flow is an important parameter as it significantly affects the filling behavior and casting quality. In order to reduce the internal porosities of the casted part, generally, most volume of the cavity is filled during the time of slow shot [3]. The velocity and length of slow shot sleeve were $0.4 \mathrm{~m} / \mathrm{s}$ and $245 \mathrm{~m}$, respectively. The velocity and length of fast shot sleeve were $1.6 \mathrm{~m} / \mathrm{s}$ and $100 \mathrm{~m}$, respectively. In this case, $95 \%$ of cavity was filled by the slow shot. The size and volume of the part on Figure 1 were $170 * 170 * 126 \mathrm{~mm}$ and $263,065 \mathrm{~mm} 3$, respectively. The casting parts were meshed into 0.92 million elements.

3) Simulation and post-process:Casting simulation of each model had been conducted based on the given condition on Table 1 with Any Casting. On the filling of the casting process, the melted material flows along the runner and enters into the cavity where the casting is molded. After the cavity is filled up, the extra melt, dirty metal and the air in the melt go into the overflow portion.

Figure 4 presents the filling process and the position of the Melt Front Advancement (MFA) during the filling process. MFA describes the movement status of the melt flow and the arrival sequence in the filling processes $[4,5]$. It also shows the melt position for the given percentage of the filling. The flow phenomenon and defects can be revealed and identified with MFA. In addition, the last area to be filled up is usually the location of overflow which is the container of dirty melt and air [6].

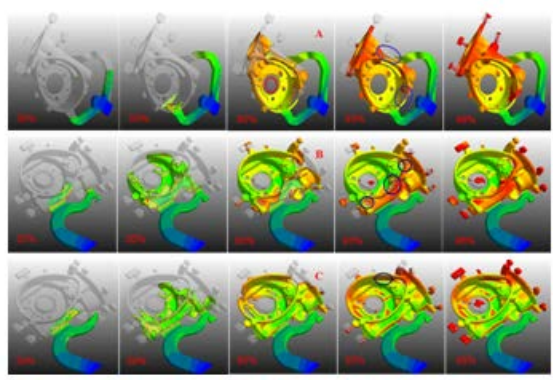

FIGURE IV. SIMULATION RESULT OF MOLD FILLING: (A) CASE 1; (B) CASE 2; (C) CASE 3.

On filling process shown on figure 4 , case 1 had nonuniform and worse flow comparing with other casting layouts. The layout of case 1 could not be used for the tool design of this part. The detail discussion for case 2 and 3 is described on the next section. 


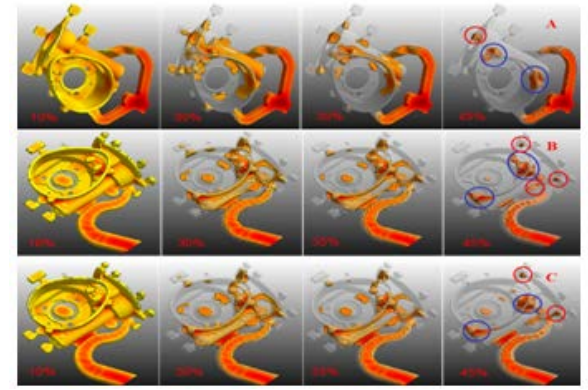

FIGURE V. SIMULATION RESULT OF SOLIDIFICATION: (A) CASE 1; (B) CASE 2; (C) CASE 3.

The solidification is conducted after finishing the filling process. The solidification result is used to identify and determine areas of excessive shear heating in thick areas or excessive cooling in thin areas. Ideal result shows uniform temperature distribution. Usually, the thick area contains a lot of heat and presents the hottest areas which are the last solidification area [6]. On figure 5 , case 1 shows a little different result comparing with case 2 and case 3 which have a similar result. Due to the solidification shrinkage, defects might be occurred on those similar areas (Blue color) as shown on $45 \%$ of solidification on Figure 5.

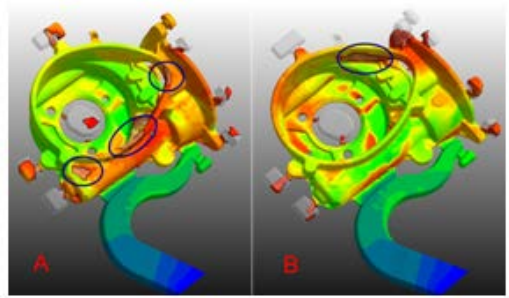

FIGURE VI. SIMULATION RESULTS AFTER 93\% FILLING: (A) CASE 2; (B) CASE 3.

\section{RESULT \& DisCUSSION}

To evaluate the simulation results of case 2 and 3, figure 6 shows the regions for the entrapped air for each case and also shows any risks for the porosity to be founded when the part is casted. Generally, overflows on the regions should be added to solve those problems. As shown on figure 6, the last area to be filled up and the flow junction zone are a big difference between each case. In case 2 on figure 6 , the flow junction zones (Blue cycle) are located on the upper cavity near into the gate. Overflows cannot be added on the flow junction zones because of their location when the porosities are founded after casting the part. On the other hand, the flow junction zones (Blue cycle) for case 3 are located on the opposite site of the gate.

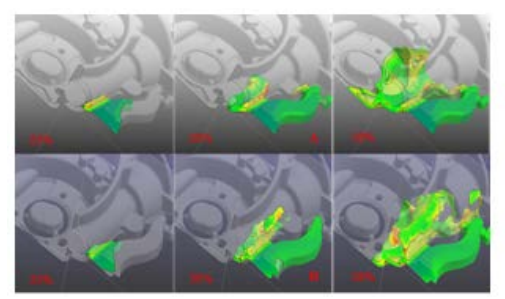

FIGURE VII. SECTION VIEW OF MOLD FILLING: (A) CASE 2; (B) CASE 3.
On figure 7 , the flow direction of each case shows the different flow pattern when the melt flows into cavity at the beginning. Due to the gate direction on figure 3, the melt flows into the bottom of cavity and come back to the top of the cavity shown on figure 4(Case 2). On the other hand, the melt flows simultaneously into the bottom and top of cavity shown on figure 4(Case 3). Hence, the flow junction zones (Blue cycle) of case 3 are located on the opposite site of the gate shown on figure 6 . Overflows can be added easily on the flow junction zones when the porosities are founded after casting the part.

Based on the above discussion and comments of the previous section, new casting design is created as shown on figure 8. Comparing with the previous casting design on figure 3 , the final casting design has a chill vent added on the opposite site of the gate shown on figure 8 . Simulation results with the final casting design had been conducted as shown on figure 9. According to the filling process on figure 9, some problems (such as flow balance, flow junction zone, etc.) are improved a lot by adding a chill vent on the opposite site of the gate. The final casting design has much better flow direction and also better uniform flow comparing with the simulation results of case 3 shown on figure 4 .

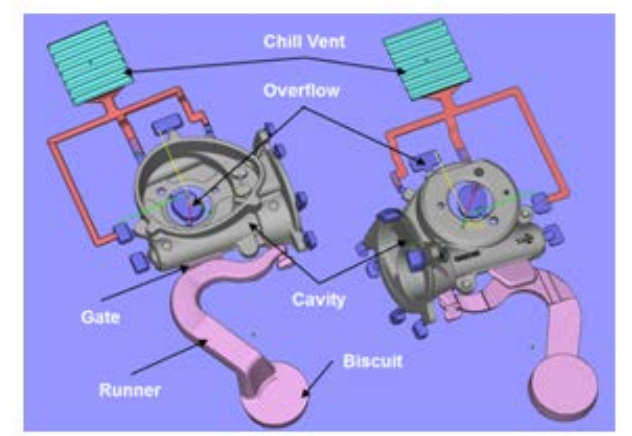

FIGURE VIII. FINAL TOOL DESIGN OF HOUSING.

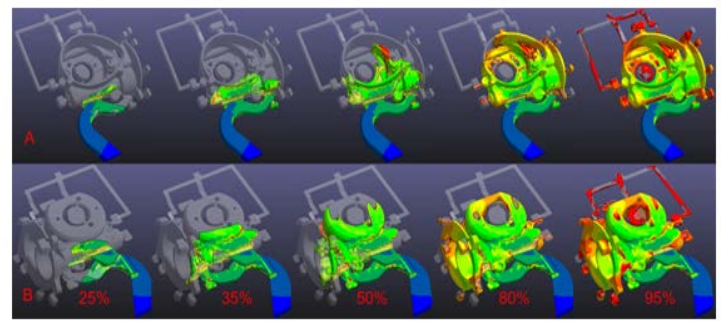

FIGURE IX. SIMULATION RESULT OF MOLD FILLING WITH THE FINAL TOOL DESIGN OF HOUSING (A) VIEW OF THE MOVING SIDE; (B) VIEW OF THE FIXED SIDE.

\section{CONCLUSION}

In current casting industries, the design and development of a casting product and process are a trial-and-error process based on heuristic know-how. The solution achieved in such a way lacks scientific calculation and analysis [7]. Using CAE simulation with Any Casting, the following results had been achieved:

- According to the filling process, the casting layout of case 3 was better than case 2 because of the location of the 
flow junction zone and the uniform and even filling into the mold cavity.

The overflow on the bottom center is useful concept to absorb the entrapped airs generated on the last area to be filled up. So, the porosity issues on the bottom regions might be reduced due to add them on the bottom center.

- As shown on figure 9, the chill vent is useful concept to solve problems for flow balance. By adding it, flow direction is much better and also uniform flow is achieved comparing with other casting design. By applying the final casting design on figure 9 into a production HPDC mold, the simulation results on figure 9 has to be verified.

\section{ACKNOWLEDGEMENT}

Funding for this paper was provided by Namseoul University.

\section{REFERENCE}

[1] K. K. Seo, Simulation Study and Application on HPDC Process with Automobile Part, Advanced Material Research, Vol.658 (2013), p.281.

[2] Y. C. Kim, Optimization of the Thin-walled Aluminum Die Casting Die Design by Solidification Simulation, Journal of The Korea Foundry Society, Vol.28 (2008), p.190.

[3] E. S. Kim, Evaluation of Diecasting Mold Cooling Ability by Decompression Cooling System, Journal of The Korea Foundry Society, Vol.29 (2009), p.138.

[4] S. C. Chen, Numerical simulation and experimental verification of melt front advancements in coinjection molding process, An International Journal of Computation and Methodology, Vol.28 (1995), p.503.

[5] Information on http://www.ptonline.com/kc/articles/moldflow-andsimulation/flow-analysis.

[6] J. Y. Park, Optimization of Casting Design for Automobile Transmission Gear Housing by 3D Filling and Solidification Simulation in Local Squeeze Diecasting Process, Korean Journal of Materials Research, Vol.16 (2006), p.668.

[7] K. K. Seo, Analysis of HPDC Process with Automobile part (Oil Pan) by CAE Simulation, Advanced Materials Research, Vol.753 (2013), p.1318. 